\title{
EMBEDDED METALLIC BANGLE IN VAGINA
}

\author{
Gupta $\mathrm{T}^{1}$, Gupta $\mathrm{N}^{2}$, Bhatia $\mathrm{P}^{3}$, Gupta $\mathrm{S}^{4}$, Jain $\mathrm{J}^{5}$
}

\begin{abstract}
BACKGROUND: Uterovaginal prolapse is a very common morbidity among Indian women. Vaginal pessaries still have role in the management of uterovaginal prolapse. Long forgotten pessaries get incarcerated in the vagina and their removal poses problems. A 65 year old postmenopausal lady presented with pain lower abdomen and thin vaginal discharge. Speculum examination revealed embedded metallic bangle in the vagina. Attempts at removal by gentle traction resulted in pain. Metallic bangle was removed under general anaesthesia and biopsy from the overlying tissue revealed no evidence of malignancy. Vaginal pessary gives symptomatic relief and does not cause any discomfort, women tend to forget it. This case report is unique as here ordinary metallic bangle was used as a vaginal pessary and in spite of long duration it did not cause much discomfort or any serious complication.
\end{abstract}

KEYWORDS: Embedded bangle, Pessary, Prolapse

1. Associate Professor, Employee State Insurance Post Graduate Institute of Medical Science and Research, New Delhi, India

2. Assistant Professor, Employee State Insurance Post Graduate Institute of Medical Science and Research, New Delhi, India

3. Professor, Employee State Insurance Post Graduate Institute of Medical Science and Research, New Delhi, India

4. Senior Consultant, Employee State Insurance Post Graduate Institute of Medical Science and Research, New Delhi, India

5. Post Graduate Student, Employee State Insurance Post Graduate Institute of Medical Science and Research, New Delhi, India

\author{
For Correspondence \\ Dr. Taru Gupta \\ Associate Professor, \\ Employee State Insurance \\ Post Graduate Institute of Medical Science and Research, \\ New Delhi, India \\ Email: tarugupta1971@yahoo.com
}




\section{INTRODUCTION}

Uterovaginal prolapse is a very common entity in Indian women. The incidence is difficult to ascertain as many women do not seek medical advice. It has been estimated that a half of parous women lose pelvic floor support resulting in some degree of prolapse, and among these women $10-20 \%$ seek medical care. Patient may present with mass coming out through the introitus, abnormal discharge, urinary or bowel complaints or low backache. Though the definitive treatment is surgery, pessary insertion is a low risk and effective nonsurgical treatment option for pelvic organ prolapse. Indications for pessary insertion include symptomatic prolapse and when surgery is not desired or recommended. It is very important to explain to the patient that the pessaries needs to be changed every three months and earlier if there is pain, excessive or foul smelling discharge or bleeding per vaginum or urinary symptoms. It is usually well tolerated and does not cause serious morbidities but if forgotten may lead to ulceration and fistula formation. We are reporting a case of forgotten incarcerated metallic bangle detected in the vagina possibly inserted for prolapse.

\section{CASE REPORT}

A 65 year-old lady presented to gynaecological outpatient department of ESI-PGIMSR New Delhi with pain lower abdomen and discharge per vaginum since 2-3 years. The pain was dull aching and the discharge was thin without foul smell. She had achieved menopause 15 years back. She was para 6 (P6L6) with all full term normal home deliveries \& had last child birth 25 years ago. There were no urinary or bowel complaints.

After thorough general examination, local examination was done. Per abdomen examination revealed no abnormality. On per speculum examination, there was a metallic bangle lying in vagina, Cervix was healthy looking. Bangle was free anteriorly but appeared to be adherent posteriorly. Per vaginal examination showed atrophic uterus with a metallic bangle lying free in anterior vaginal wall but embedded on both posterolateral sides to the vagina. Attempts at removal by traction resulted in pain. On Per rectal examination rectal mucosa was free.

Patient was informed about the presence of metallic bangle embedded in the vagina \& tried to elicit the history of its insertion. Patient could not recollect anything regarding its insertion done by whom and when. Counselling was done regarding the removal of bangle after proper work up. Ultrasound Pelvis showed a normal sized uterus and no adnexal lesion. There was a linear echogenicity seen in vaginal region. The interface between posterior vaginal wall and rectum appeared normal.

Non Contrast Computed Tomography (NCCT) Pelvis showed evidence of rounded hyperdensity of $5 \mathrm{~cm}$ diameter seen in vaginal region. The fascial planes anteriorly between vagina and bladder and posteriorly vagina and rectum appeared to be maintained.

The patient was posted for removal of incarcerated metallic bangle in the vagina under general anaesthesia. With gentle traction on the bangle, overlying fibrosis was released using surgical knife over the incarcerated foreign body from both posterolateral aspects of vagina. Biopsy from tissue covering the bangle reported no evidence of malignancy. She was treated with broad spectrum antibiotics for seven days.

\section{DISCUSSION}

In general pessary treatment of genital prolapse is a technically easy and quick procedure. Most of the time use of pessary is not associated with serious morbidities. Commonly rubber ring pessaries are used for this purpose. Our case is worth reporting because ordinary metallic bangle was used as pessary and inspite of being there for long duration; it did not cause much discomfort or any serious complication. Though the metallic ring must have caused ulceration at some time and later it got embedded inside the vaginal mucosa, it had not eroded into the urinary bladder or rectum.

When it gives symptomatic relief and does not cause any discomfort, women tend to forget it. Forgotten ring pessary can erode into rectum causing rectovaginal fistula ${ }^{2}$, erode into the urinary bladder causing vesicovaginal fistula ${ }^{3}$, Long forgotten vaginal pessaries get incarcerated in the vagina and their removal poses problem. Dasari P reported a case where a metallic bangle was used as a pessary and postmenopausal patient presented with foul smelling purulent discharge. ${ }^{4}$ Uprety DK reported a case with metallic vaginal ring pessary for 16 years without significant symptoms.'

\section{CONCLUSION}

Vaginal pessaries still have role in the management of uterovaginal prolapse especially in elderly women, unfit for surgery and as a temporary relief for women waiting for 


\section{Case Report}

surgery. Counselling about its use and need of regular follow up should be stressed upon as forgotten vaginal pessaries may cause serious complications.

Figure 1: showing embedded metallic bangle in the vagina

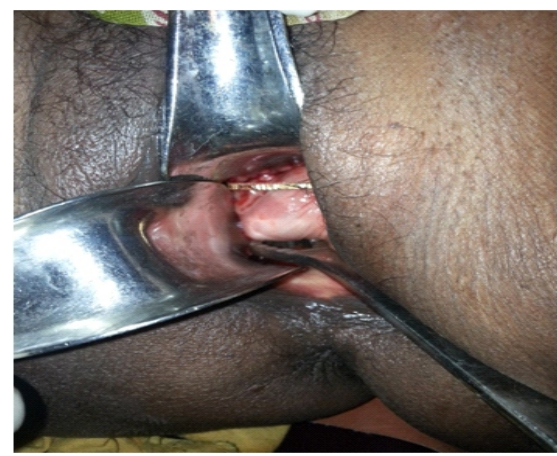

Figure 2 : NCCT Pelvis showing rounded Hyperdensity in vaginal region

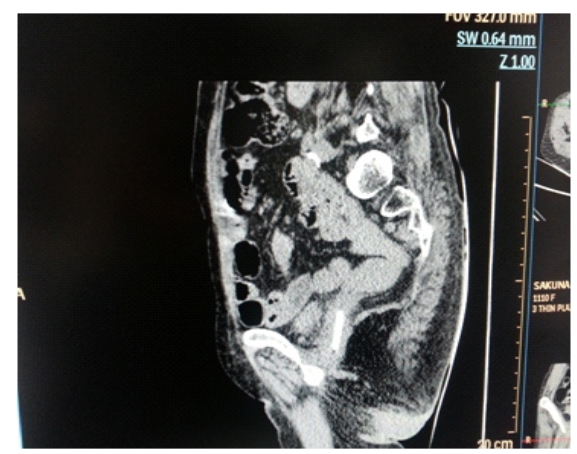

Figure 3 : NCCT Pelvis showing rounded $(5 \mathrm{~cm}$ in diameter) Hyperdensity in vaginal region

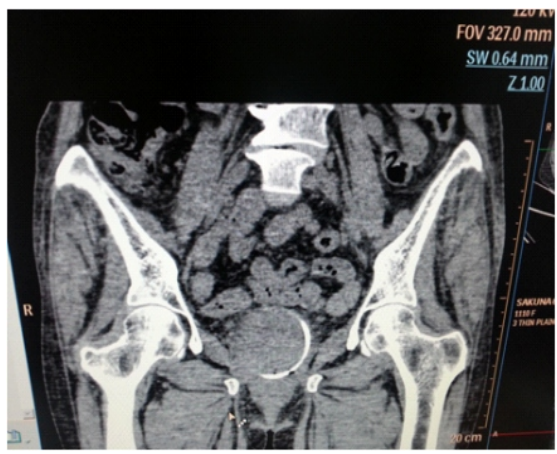

Figure 4: showing release of bangle from posterolateral aspect of vagina

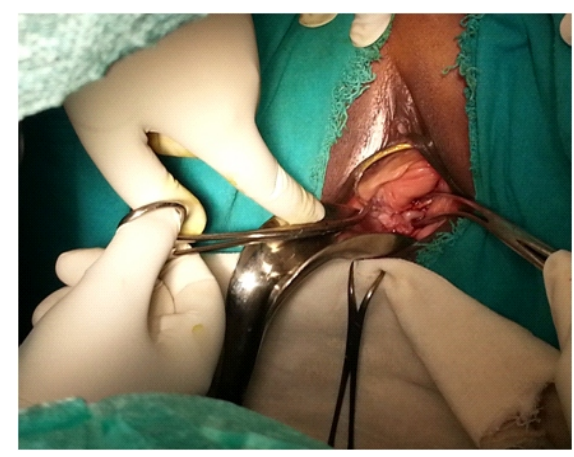

\section{REFERENCES}

1. Thakar R, Stanton S.Management of genital prolapse.BMJ 2002;324:1258-62. http://dx.doi.org /10.1136 /bmj. 324. 7348.1258

2. Hanavadi S, Durham Hall A, Oke T, Aston N.Forgotten vaginal pessary erding into rectum.Ann R Coll Surg Engl 2004;86:1-2. http://dx.doi.org/10.1308/147870804182 PMid:16749957 PMCid: PMC1964320

3. Wheeler LD, Lazarus R, Torkington J, O'Mahony M S.Perils of pessaries. Age and ageing 2004;33:510-1. http://dx.doi.org/ 10.1093/ageing/afh170PMid:152716404.

4. Dasari P, Sagili H.Incarcerated foreign body in the vagina-a metal bangle used as a pessary.BMJ Case Rep. 2012 May 11.

5. Uprety DK, Regmi MC, Budhathoki B, Tiwari RR, Subedi S, Chhetri S.Metallic vaginal ring pessary: A rare entity.Kathmandu University Medical Journal 2008;24:508-10. 